\title{
Trilobed flaps: an alternative to dorsal nasal flaps
}

\author{
Nathaniel J Jellinek ${ }^{1,2,3}$ and Alyssa B Findley ${ }^{3}$ \\ ${ }^{1}$ Department of Dermatology, The Warren Alpert Medical School at Brown University, Providence, RI, USA \\ ${ }^{2}$ Division of Dermatology, University of Massachusetts Medical School, Worcester, MA, USA \\ ${ }^{3}$ Dermatology Professionals, Inc. East Greenwich, RI, USA
}

\begin{abstract}
Trilobed flaps have demonstrated utility in the reconstruction of lower nasal defects. An understanding of the flap dynamics, particularly when compared to and contrasted with that of the dorsal nasal flap, enable the surgeon to employ this flap in a variety of circumstances. This paper describes the use of this flap and demonstrates its benefit through detailed figures.
\end{abstract}

\section{Introduction}

Partial thickness nasal defects on the tip, supratip, and lateral tip pose unique reconstructive challenges, and have been approached successfully with a variety of surgical techniques. The dorsal nasal (Reiger) rotation flap [1] is a widely used reconstruction that preserves distal nasal contour as a sliding flap, with elements of both rotation and advancement, accessing the reservoir of lax dorsal nasal and glabellar skin. The repair comes at the cost of lengthy suture lines, ideally hid along the nasofacial sulcus and in the glabella, but always with an oblique distal nasal suture line at the site of standing cone repair. When designed and executed correctly, the results are elegant, and often a preferred alternative to a skin graft or other local flaps. Still, alar asymmetry and tip elevation remain possible complications, although these are usually prevented with proper patient selection, flap design and surgical execution.

\section{Method}

The trilobed flap, as recently described and detailed by Albertini and Hansen, is an elegant technique to approach lateral tip lower nasal defects. However, the flap has been detailed with different emphasis previously [2-6]. In the past three years of practice, the senior author (NJ) has utilized the trilobed flap for a variety of defects traditionally approached with the dorsal nasal flap. It has become clear that, just as the bilobed flap has comparable features to the hatchet flap for lower lateral nasal defects [7], the trilobed flap can be compared to the dorsal nasal flap and be utilized for supratip, tip, and lower dorsum defect reconstruction.

\section{Result}

Both the bilobed and trilobed flaps contain significant elements of rotation and transposition in their design, in addition to an important but subtler element of advancement [8]. Taking into account Zitelli's significant redesign of the bilobed flap [9] and subsequent modifications [10,11], the authors' design their trilobed flaps around a standing cone and pivot point that dictates subsequent arcs of rotation and transposition. (Figures 1-3) For lateral and inferior defects, the standing cone is placed just above the alar groove when possible, angled quite obliquely (rather than horizontally) (Figure 4). The oblique vector of the standing cone not only places the incision line in or abutting an optimal anatomic subunit boundary line, but it limits "bulldozing" of the free margin in overly sebaceous skin when the flap transposes and rotates into the primary defect [10]. Instead of a tension vector compressing the free margin vertically, the tension vector of the primary defect is oriented obliquely towards the midline.

\section{Discussion}

The trilobed flap has several advantages in this location over the bilobed flap. The latter incorporates a design with a standing cone and two lobes of near equal size, approximately 45 degrees between them. With some nasal defects, this particular design places the secondary lobe in a nasal location that risks ipsilateral or contralateral alar elevation [11] when closing. Increasing the angles between arcs can more specifically place the secondary lobe (and tertiary defect) in a more advantageous location but creates a flap that transposes and rotates with greater difficulty, under more tension and a risk of secondary tissue movement and alar distortion. As noted by previous authors, the trilobed flap addresses these very concerns and facilitates flap design with more ideal 45 degrees of rotation per lobe, and with a tertiary lobe oriented perpendicular to the free margin [12]

When nasal defects are located on the supratip and tip skin, (sites commonly approached with the dorsal nasal flap,) the authors have utilized a similar approach to that of those on the lateral nasal tip skin. The standing cone is designed first, often oriented obliquely and superiorly, and long enough that the apical angle is 30 degrees (to minimize dog-ear formation). The flap is designed around this pivot point, with arcs drawn and lobes created of equal or near equal size (Figures 1-3). The final flap design including exact lobe size and length is altered to a small degree on a case-by-case basis, based on a variety of factors: tissue swelling at time of reconstruction, elasticity/stiffness of the nasal skin, surrounding scar and/or any limitation of the flap to

Correspondence to: Nathaniel J Jellinek, 1672 South County Trail, Suite 101, East Greenwich, RI 02818, Tel: (401)-885-6647; Fax: (401)-885-6639; E-mail: winenut15@yahoo.com

Received: April 18, 2016; Accepted: May 09, 2016; Published: May 13, 2016 

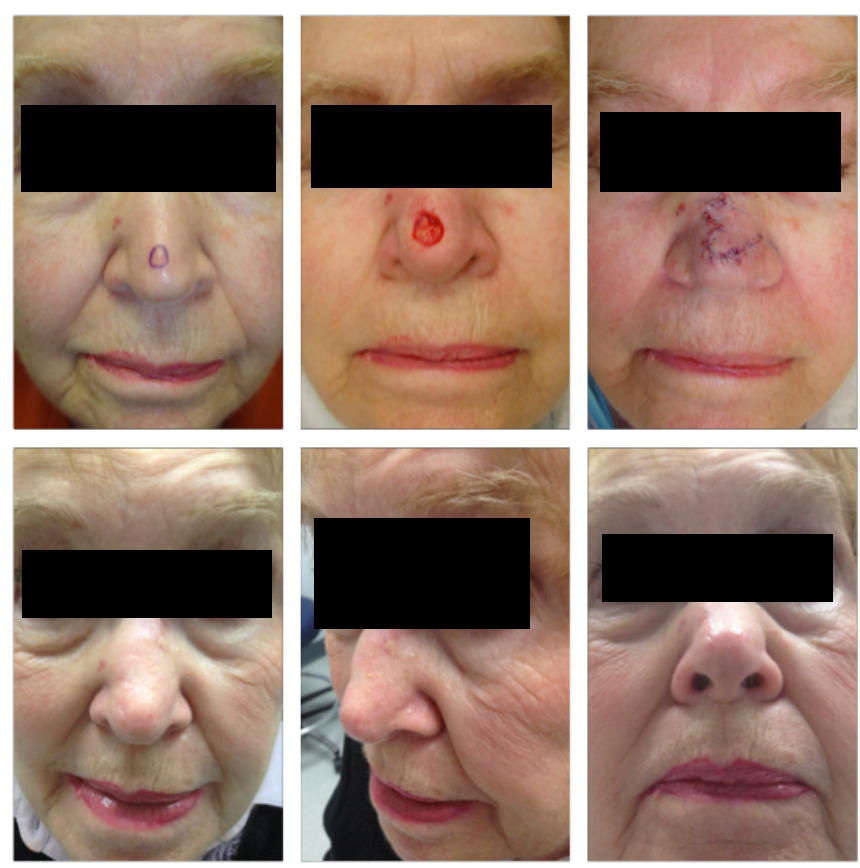

Figure 1. Patient with $1.2 \mathrm{~cm}$ defect on the midline nasal supratip, repaired with a trilobed flap. The standing cone is designed obliquely to the patient's left, minimizing downward compression of the left ala. One month follow-up images are presented.
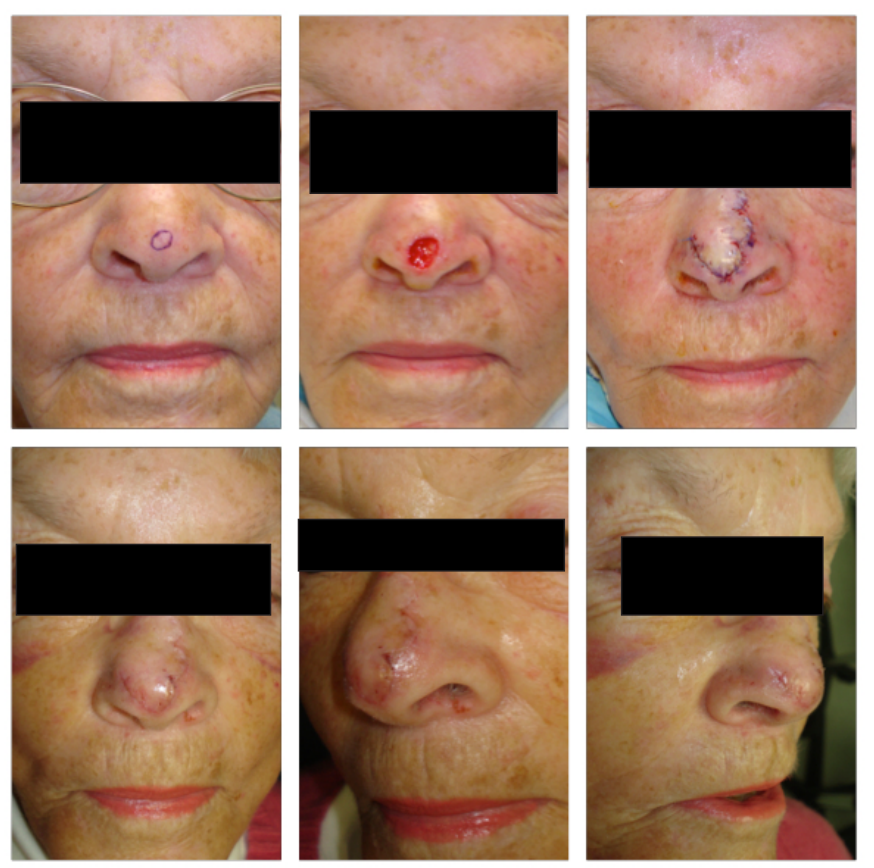

Figure 2. Patient with $1.2 \mathrm{~cm}$ defect on the midline nasal tip, repaired with a trilobed flap The standing cone is designed superiorly and obliquely to the patient's right. The tertiary lobe is located in the midline nasal root, a source of great tissue laxity. One week follow-up pictures are presented.

rotate freely with pivotal restraint [13].

When viewing the arcs of rotation in this location with this flap design, the trilobed flap resembles a shortened dorsal nasal flap [14] without extension to the glabella, and a back-cut in the form of the tertiary lobe on the upper nose (Figure 5). Due to the lengthening of this flap through the series of $z$-plasties inherent in the flap mechanics [10], greater flap mobility is achieved, and the standing cone position is idealized based on original design.

Conceptually, this surgical approach is in direct contrast to the way
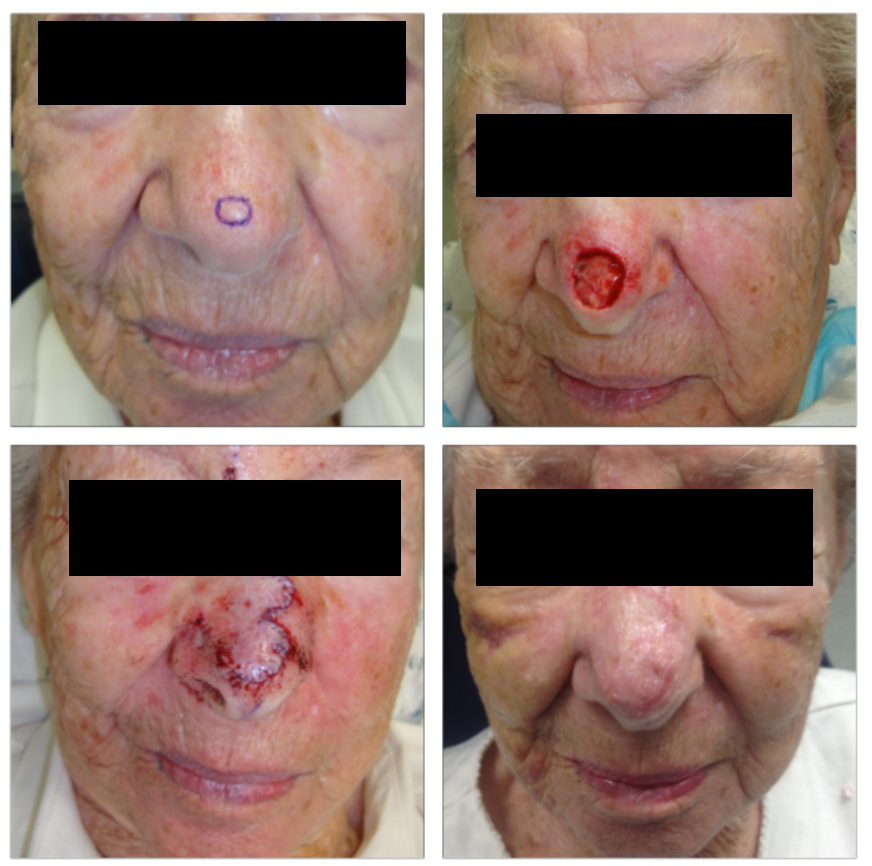

Figure 3. Patient with $1.4 \mathrm{~cm}$ defect on the midline nasal tip and supratip, repaired with a trilobed flap. The standing cone is designed superiorly and obliquely to the patient's right. The tertiary lobe is located in the right medial canthus. One week follow-up pictures are presented.
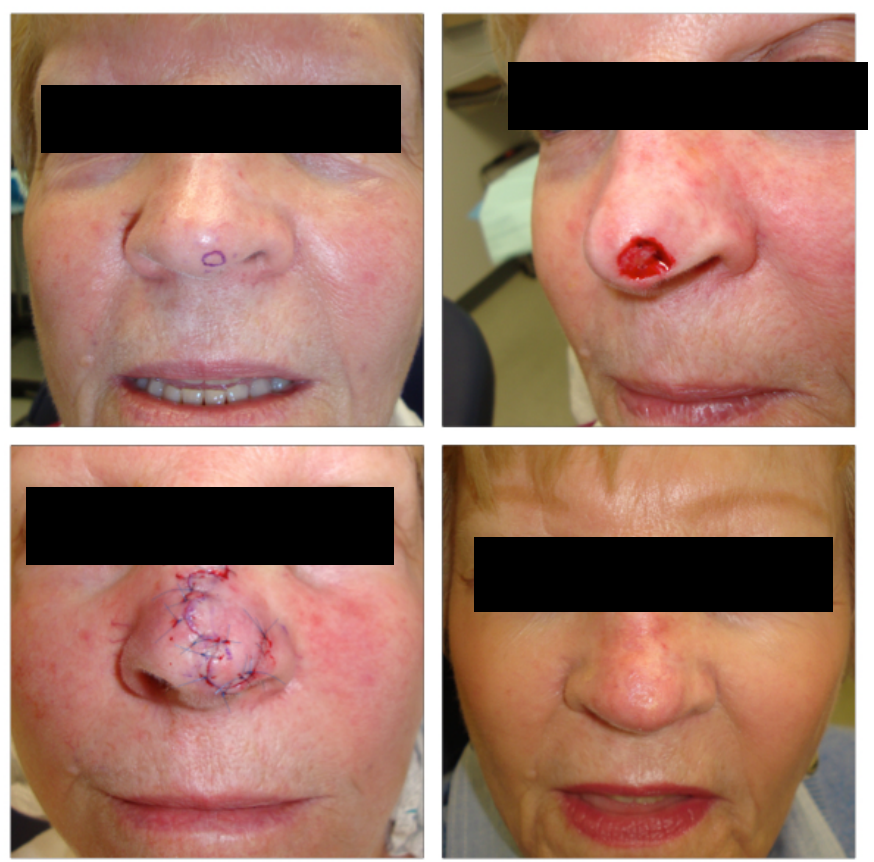

Figure 4. Patient with a $1.3 \mathrm{~cm}$ defect on the left nasal tip and infratip. The flap is designed around a standing cone and pivot point located superiorly and obliquely to the patient's left. The tertiary lobe is oriented perpendicular to the left ala. One month follow-up pictures are presented. 

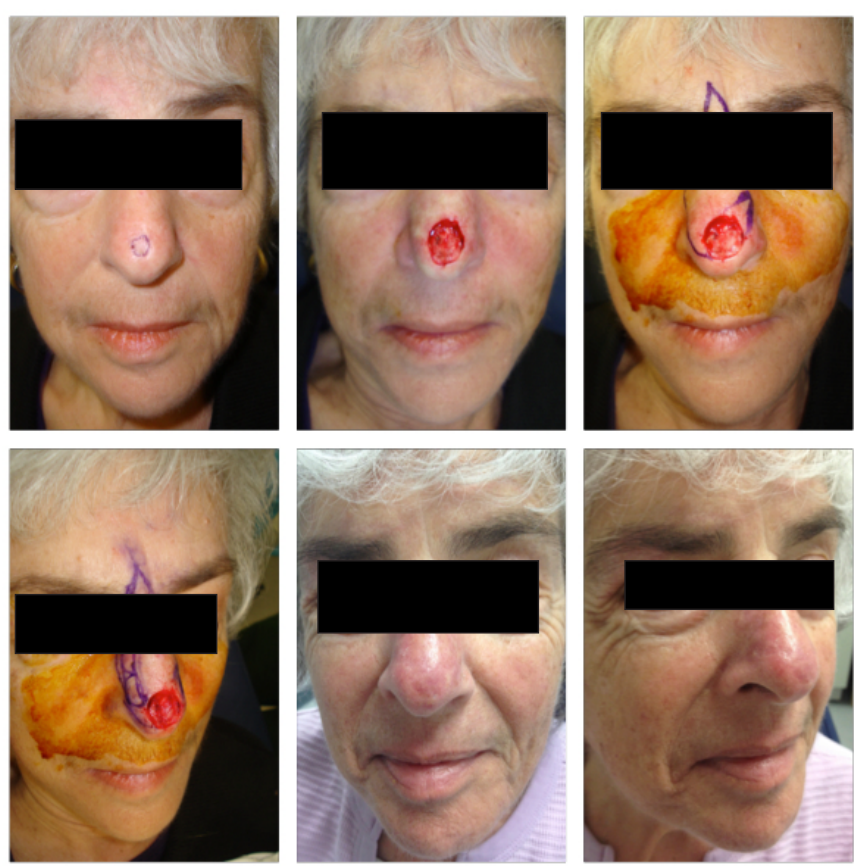

Figure 5. Pt with $1.7 \mathrm{~cm}$ defect on the nasal tip and supratip. An example of a dorsal nasa flap design is shown marked, with the trilobed flap also drawn, then executed. Two month follow-up pictures are presented. There is slight elevation of the right alar rim.

many surgeons perform the dorsal nasal flap [15]. In most instances, the dorsal nasal flap is designed with an idealized take-off point, carried superiorly in the nasofacial sulcus, crossing towards the midline in the glabella, with a generous back-cut at the flap apex superiorly. Only after the flap is undermined, rotated and advanced is the standing cone designed, usually obliquely across the nose. Occasionally this final step in design is performed with the standing cone placed more laterally to avoid cutting in to the flap pedicle, and/or shortened such that the apical angle is less than 30 degrees. The aesthetic sequelae from these design flaws increases the likelihood of an inelegant result, with scar lines, nasal asymmetry, and tissue swelling that are distracting and may require revision.

The comparison between the trilobed flap and dorsal nasal flap can be visualized in the figure. Due to the greater tissue mobility achieved with the multilobed flap, there is no need to extend the skin incisions superiorly to the glabella, and the natural superior incisions (and true reservoir) lie in the upper sidewall and medial canthal nasal skin. Indeed, this flap depends on (and is limited by) the tissue laxity found on the upper nose. As such, patients with tight nasal skin, previous radiation, or previous surgeries on the nose may benefit from other reconstructive options.

\section{Conclusion}

The lessons learned from decades of bilobed flap experience, and now years of trilobed flap use, have created a flap with predictable tissue movement and outcomes. As noted, patient and defect selection are crucial, however with optimal flap design and execution, the trilobed flap can reconstruct lower nasal defects as an alternative to the dorsal nasal flap and other reconstructive options.

\section{References}

1. Johnson TM, Swanson NA, Baker SR, Brown MD, Nelson BR (1995) The Rieger flap for nasal reconstruction. Arch Otolaryngol Head Neck Surg 121: 634-637. [Crossref]

2. Copcu E, Sivrioglu N, Koc B, Er S (2006) Reconstruction of the lateral canthus with trilobed skin flap and temporalis fascia graft. Plast Reconstr Surg 117: 2514-2516. [Crossref]

3. Copcu E, Yazici M, Etensel B, Yüreklý Y, Balkaya M (2003) The study of expanded tri-lobed flap in a rabbit model: possible flap model in ear reconstruction? BMC Surg 3: 13. [Crossref]

4. Iida N, Ohsumi N, Sakai M (1997) A trilobed flap for reconstruction of nasal skin defects. Plast Reconstr Surg 100: 991-995. [Crossref]

5. Ohtsuka H, Miki Y, Shioya N (1982) Trilobed flap in facial reconstruction. Br J Plast Surg 35: 493-497. [Crossref]

6. Harashina T, Maruyama Y, Kitamura K (1977) The trilobed flap. Case report. Plast Reconstr Surg 60: 623-624. [Crossref]

7. Zilinsky I, Farber N, Haik J, Weissman O, Friedman T, et al. (2012) The hatchet and bilobed flaps revisited: shedding new light on traditional concepts. J Drugs Dermatol 11: 99-102. [Crossref]

8. Martinez JC (2013) Commentary: bilobed flap for reconstruction of small alar rim defects. Dermatol Surg 39: 653-654. [Crossref]

9. Zitelli JA (1989) The bilobed flap for nasal reconstruction. Arch Dermatol 125: 957959. [Crossref]

10. Cook JL (2000) A review of the bilobed flap's design with particular emphasis on the minimization of alar displacement. Dermatol Surg 26: 354-362. [Crossref]

11. Cook JL (2005) Reconstructive utility of the bilobed flap: lessons from flap successes and failures. Dermatol Surg 31: 1024-1033. [Crossref]

12. Albertini JG, Hansen JP (2010) Trilobed flap reconstruction for distal nasal skin defects. Dermatol Surg 36: 1726-1735. [Crossref]

13. Dzubow LM (1987) The dynamics of flap movement: effect of pivotal restraint on flap rotation and transposition. J Dermatol Surg Oncol 13: 1348-1353. [Crossref]

14. Tan E, Mortimer NJ, Hussain W, Salmon PJ (2010) The nasal sidewall rotation flap: a workhorse flap for small defects of the distal nose. Dermatol Surg 36: 1563-1567. [Crossref]

15. Zimbler MS, Thomas JR (2000) The dorsal nasal flap revisited: aesthetic refinements in nasal reconstruction. Arch Facial Plast Surg 2: 285-286. [Crossref]

Copyright: (C2016 Jellinek NJ. This is an open-access article distributed under the terms of the Creative Commons Attribution License, which permits unrestricted use, distribution, and reproduction in any medium, provided the original author and source are credited. 